\title{
Time Series Analysis on Reported Cases of Measles in Makurdi, Nigeria (1996 - 2005)
}

\author{
Asongo, A.I ${ }^{1}$, Jamala, G. $\mathrm{Y}^{2}$ and Waindu, $\mathrm{C}^{2}$ \\ ${ }^{1}$ Modibbo Adama University of Technology, Yola, Nigeria \\ ${ }^{2}$ College of Agriculture, Ganye, Adamawa State, Nigeria 2
}

\begin{abstract}
The study analyzed some reported cases of measles in the Federal Medical Centre, Makurdi, from 1996-2005. The data were collected from the Clinical Report Unit. The method of least squares and moving average were used in the trend estimation and seasonal variation of data and projecting trend. The findings revealed that the study area has high record cases of measles as from November to March. This period of the year is usually characterized with severe heat. In a nutshell, measles occur most during hot seasons.
\end{abstract}

Keywords: Time Series, Measles, Analysis, Clinical, Seasonal, Estimation

\section{Introduction}

Most often, both as a sequence of the widespread application of scientific attitude, and methods, and because of the increasing number of record in our everyday life, in medical field, business, economic, social sciences as well as in the physical sciences, the study of statistics has shared in this growth. Statistics helps in planning and in coping with the changes occurrences of certain cases. It encompasses all operation involve from the planning of the first assembly of data to the final presentation or conclusion.

Our knowledge of such things as hospital records, total number of staff, and total number of students in an institution etc would not have been so definite and precise, if there were no reliable pertaining to each one of this. To say that the total number of staff in mathematics department is small is a vague statement. "Small' to one individual may mean one thing while to another it might mean something else altogether. One may take it to be near 50 while another may think it to be in the neighborhood of 100 . But the moment we say that the numerical strength of staff of Mathematics' department of an institution is 70 we make a statement which is precise and convincing. It can thus be said that statistics increase the field of mental vision as an opera glass or telescope increases the speed of physical vision.

Administrators in all organization make plan to cope with future changes. The planning function looks to the future. The plan is to make decision in advance about future cause of action. Obviously, then planning and decision-making are based on Forecast or expectation of what the future holds. Thus, whether they employ simple intuitive managerial guess or complex methods, administrators must look down the road and make this forecast.

Generally, among the statistical tools used in planning and in coping with changes is Time Series. This is a collection of observation made sequentially over a period. The records of reported cases of chickenpox, measles, HIV, the monthly sales of a company over a number of months are examples of time series. The time can be days, weeks, months, years, decades or even seconds. By example, a medical team may be interesting in improving the health condition of a community that suffers in from polio using the past record obtained. In order to do this more thoroughly, statistical techniques have to be employed to analyze the data- this device is called "Analysis of Time Series Data".

Time series analysis is a very useful aspect in statistics that is helpful and applicable in all field of human endeavor. Its primary purpose is discovering and measuring the various influences for the observed values and data obtained. These are useful in understanding the past behavioral pattern, evaluating current accomplishment, planning future operation and comparing different time series.

The study of the past behavior of any observed data enables us to predict future tendencies, to (i.e. measles) is therefore of great assistance. For it is with the help and analysis of this data that approximately correct time to carryout immunization in the future will be known.

In addition, the knowledge of the behavior of the variable enables statistician to iron out inter-year variation, thus, seasonal fluctuation may be reduced by taking effective decisions or plans before time.

\section{TIME SERIES MODEL}

This is an equation, which describes how variations components combine to form individual data value. It is an empirical combination which meant to represent a phenomenon or a reality such that it follows a consensus, for examples

$\mathrm{E}=\mathrm{T} \quad$ is a model 


\section{TIME SERIES CYCLE}

Time series cycle is a process whereby time series data exhibit a general pattern, which broadly repeats itself over number of times.

\section{LONG TERM CYCLICAL FACTOR}

This can be taught of (if it exists) as due to underlying external factor causes outside the scope of the immediate environment.

\section{SEASONAL VARIATION}

This refers to the irregular upwards and downwards movements exhibited by the time series plots. Such movements are usually due to recurring events which take place annually.

\section{RESIDUAL VARIATION}

The residual variation (or effect) is what remains of secular trend after the secular, cyclical and seasonal components have been removed. Part of the residual may be attributed to unpredictable rare events (such as earthquake, road accidents, sudden outbreak of a disease etc) and part to the randomness of human action. In any case, the presence of residual effect emphasizes a point that no event or phenomenon should be described by deterministic models. All realistic business or medical models, time series otherwise, should induce a residual components.

\section{INDEX OF SEASONAL VARIATION}

An index of seasonal variation measures how much a time series changes on a relative basis with respect to an average for the period of (a year or less). If a time series is reported on a quarterly basis, four seasonal index numbers are prepared each year; and those numbers are expressed as a percentage relative to a quarterly value. If monthly data are used, there are twelve (12) seasonal index numbers each year and this number are expressed as a percentage relative to a quarterly average monthly value.

Measurement of these seasonal variation help in these ways:

- $\quad$ To understand seasonal patterns

To project existing patterns into the future and

To eliminate seasonal components.

Richmond (1957), defined Time series as a set of observation on the same variable, such that the observations are orders in time, the successive observation differ among themselves, not only because of sampling variations and other chance or random effects, but also because the true value of the variable being measured-the parameter, is changing over time. Thus, such chance or sampling variation as there may be in the mass of observation is supplemented by monthly or quarterly or weekly, if the data are daily-and cyclical effects, if the phenomenon is one that is influenced by the business cycle.

According to Omotosho (1999), Time series could be defined as data collected at equal intervals of time. Such intervals could be weekly, monthly, quarterly or yearly. The data 20, 17, 50, 77 is a good example of Time series, the data depicts a quarterly record of the incidence of chicken-pox in the year 1982 in a certain area.

Gupta (1989), defined Time series to be a set of data portending to the value of a variable at different times. It uses an important property, which makes it quite distinct from any other kind of statistics data. GUPTA gave some examples of time series to include the population of India at each successive decimal census, daily business handled by a bank, monthly production statistics of a steel mill; annual cases of rainfall in a geographical location.

To Sanders (1990) a time series is a set of numerical values of a particular variable listed in chronological order. Harper W.M (1971) said, "Many variables have values that change with time-exchange population, export, car registration, company sales, employment and electricity demand. Figures relating to the changing value of a variable over a period of time are called a time series.

\section{MODELS OF TIME SERIES}

Thomas (1977), maintained that a time series is likely to have affected by many external factors. For example, a general health condition of a community may be affected by general factors, like weather changes, migration of infected persons to such a place etc. In order to explain the movement resulting from the above mentioned factors of a time series data, models can be constructed which describe how various components combine to form individual data, individual data values.

Depending on the nature, complexity and extent of the analysis required. There are various types of models that can be used to describe the time series data. The components that make up each of a series are described below:

$$
\mathrm{Y}=\mathrm{T}+\mathrm{S}+\mathrm{C}+\mathrm{I} \text { (additive model) }
$$

Where, 


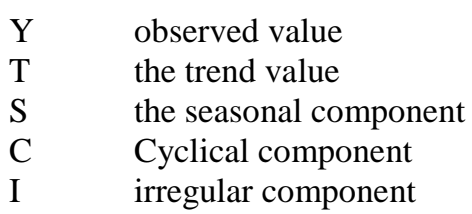

Invariably, giving a set of time series, every data, and every single given (Y) value can be expressed as the sum of four components. Namely, T, S, C and I which have been described above. The evaluation and interpretation of these components is the main aim of the over all analysis.

Francis (1988), explained the movement of time series data models which can be constructed to describe how various components are put together to form individual data values depending on the nature, complexity and the extent of the analysis defined.

Additive model as

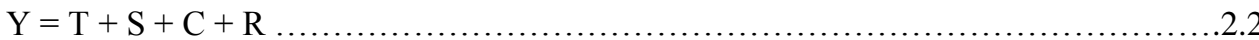

Where $\mathrm{Y}$ is the given value of the series available, $\mathrm{S}, \mathrm{C}$ are as defined above and $\mathrm{R}$ is the random or residual component.

According to Spiegel (1972), "the time series analysis" consists of description (generally mathematical) of components movement present. It is assured that the time series variable $\mathrm{Y}$ is a product of the variable T, C, S, and I that produce the trend, cyclical, seasonal and irregular movements respectively.

Mathematically,

$\mathrm{Y}_{\mathrm{t}}=\mathrm{T}_{\mathrm{t}} \mathrm{X} \mathrm{S}_{\mathrm{t}} \mathrm{X} \mathrm{C}_{\mathrm{t}} \mathrm{X} \mathrm{I}_{\mathrm{t}}$ (multiplicative model)

Each of the four components contributes to the determination of the value of $Y_{t}$ at each time period. Although, it will not always be possible to characterize each component separately, the component model provides theoretical formulation that helps the time series analyst achieve a better understanding of the phenomena affecting the path followed by the time series.

\section{FORECASTING}

Samuel (1957), had it that any decision or action made today whether in hospitals, banking, marketing, government etc must almost invariably be based on some expectation about what tomorrow will bring, and such expectation or prediction about future events and relationship is refers to as forecasting, sometimes called projecting the time series.

Forecasting can be performed at different levels, depending on the use to which it will be put. Simple guessing, based on previous figures, is occasionally adequate. However, where there is large investment at stake for example in plants stock and manpower, structural forecasting is essential.

According to Francis (1988), any forecast made, however technical or structure, should be treated with caution; since the analysis of past data will be broadly continued, at least into the short-term future.

The present study is in time with the reviewed literature in that it incorporates all the key aspects mentioned in literatures regarding of time series, analysis of time series and forecasting.

The analysis of the above components using reported cases of measles in Federal Medical Centre, Makurdi will give us a clear picture of the trend of the cases of measles reported to the centre.

\section{Materials and Methods}

The study area: The study area lies between Latitude $6^{\circ} 25^{\prime}$ and $8^{\circ} 8^{\prime} \mathrm{N}$ and Longititude $7^{\circ} 47^{\prime}$ and $10^{\circ} 0^{\prime} \mathrm{E}$. Based on Koppen's Scheme of Classification, the area lies within the AW Climate and experiences two distinct seasons, the wet/rainy season and the dry/summer season. The rainy season lasts from April to October with annual rainfall in the range of $1000-2000 \mathrm{~mm}$. The dry season begins in November and ends in March. Temperatures fluctuate between $23-37^{\circ} \mathrm{C}$. (www.benue state,gov.ng, 2012)

\section{Description of the Components}

A time series data of successive values of variable is collected at a regular time interval i.e. weekly, quarterly, or yearly; as for this work the, data is collected monthly. These variables are subjected to changes or fluctuations from time to time. These fluctuations are cause by a force that is constantly at work. These forces are divided into four main types often called components of time series.

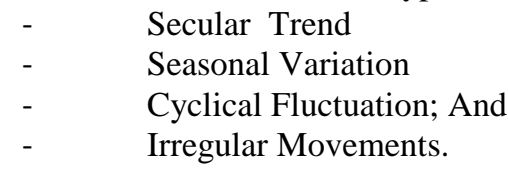




\section{Techniques of Extracting Trend Value}

A given time series has no unique set of trend values; each method will yield a different trend. Extraction of secular trend from a given set of time series is done in many ways viz.

- $\quad$ The Method Of Least Square

- $\quad$ The Free Hand Method

- $\quad$ The Semi-Average Method

- $\quad$ The Moving- Average Method

\section{The Method of Least- Square}

When it is necessary or desirable to have a mathematical equation describing the trend, the method of leastsquares is the most useful technique or method. Not only does it yields an equations, but also the line fitted by the method of least squares bears a very definite and easily understandable relationship to the observation points to which the line is fitted. The least square Equation is given as:

$\mathrm{Y}=\mathrm{a}=\mathrm{bx}$

Where;

$\mathrm{Y}=$ is the computed or trend value of the independent variable i.e. of $\mathrm{Y}$ series.

$\mathrm{X}=$ is the independent variable i.e. time unit of $\mathrm{x}$ series.

The constant $\mathrm{a}, \mathrm{b}$ are referred to as unknowns (as their values are not given in the series but are required to be determined).

Thus, the equation expresses the trend value of the series being studied as a function of time. In other words, if the equation for the trend line is known, the value on the line at any point in time may be computed from the equation by substituting for $\mathrm{x}$ the specific time for which the trend value is desired.

To determine the value for $\mathrm{a}$ and $\mathrm{b}$ we employ the following method;

$\mathrm{Y}_{\mathrm{t}}=\mathrm{a}+\mathrm{bx}$

$\mathrm{a}=\frac{\sum y}{n} ; \mathrm{b}=\frac{\sum x y}{\sum x^{2}}$

Although mathematically representative of the data, it assumes that, linear trend is appropriate. It is generally thought unsuitable for highly seasonal data.

However, for the sake of this research work, this method is used in chapter four for trend computation and forecasting.

\section{The Free Hand Method}

The simples, quickest and easiest method of estimating the secular trend is to plot the original data on a graph and then to draw a free hand smooth curves through the points so that it may accurately describe the general long-run tendency of the data. While drawing such a curve the minor short - run fluctuations or abrupt variation are taken into account.

This method has obvious disadvantages; these are;

I. There is no mathematic expression or model for the method and so its properties cannot be described

II. It depends too much on individual judgment.

III. Different individual may fit in different line.

IV. It is time consuming to construct.

\section{The Semi-Average Method}

Another method for describing the secular trend is to divide the original data into two equal parts. The values of each part are then summed up and averaged. The average of each part is centered in the period of time of the part from which it has been calculated and then plotted on the graph. Thus, a line may be drawn to pass through the plotted points.

When the data consist of an even number of values its division into parts does not present any difficulty, thus if there are ten values, each part would have five of them. But if there are odd values, the easiest procedures would be to omit the middle value. The means for each part is calculated by dividing the total of the half by its number of values. The means are plotted at points corresponding to mid- pointed of the respective parts and connected with a straight line to obtain the desired trend line. Trend value $\left(\mathrm{T}_{\mathrm{t}}\right)$ for a particular year is computed using the formula

$\mathrm{T}_{\mathrm{t}}=\mathrm{M}_{1}+\mathrm{X}_{\mathrm{c}}$

Or

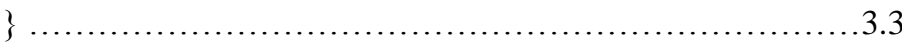

$\mathrm{T}_{\mathrm{t}}=\mathrm{M}_{2}+\mathrm{X}_{\mathrm{c}}$

Where,

$\mathrm{T}_{\mathrm{t}}=$ trend values for a particular year

$\mathrm{M}_{1}=$ Means of the first second part

$\mathrm{M}_{2}=$ Mean for the second part 
$\mathrm{X}=$ Average increment per period $\left[\mathrm{X}=\left(\mathrm{M}_{1}=\mathrm{M}_{2}\right) / \mathrm{N}\right]$

$\mathrm{C}=$ Average increment per period.

\section{The Moving Average Method}

This is based on the principle that random fluctuations can be removed from a data by averaging over a suitable period of time, and thus smoothening the data the trend them stands out clearly. It is in fact a logical extension of the semi-average method.

The moving average is a series of successive average secured from a series of values of averaging groups of $\mathrm{n}$ successive values of the series. These groups are composed as follows the first group consists of the items from the second to the $(n+1)^{\text {th }}$, third consist of items from third to the $(n+2)^{\text {th }}$, and so on. These averages give us the trend values for the middle period of each group from which they have been computed.

\section{Results and Discussion}

The data collected for the purpose of a statistical enquiry sometimes consists of a few simple figures, which can be easily understood without any kind of special treatment. However, more often there is an overwhelming mass of raw materials and detail without any form or structure. Obviously enough, most of the data obtained are in raw state for they have not gone through any statistical treatment.

This widely, unorganized, and shapeless mass of collected data is not capable of being rapidly or easily assimilated or interpreted at best only a hazy impression and that too doubtful readability may be obtained by it perusal. In order to eliminate the irrelevant details of a collected data and to allow a nonprofessional, understand vividly at a glance the data collected. It need to be condensed and simplify, this procedure is called Tabulation of Data.

\section{Extracting the Time Series Trend using Least Square Method}

Table 1 shows the trend calculation of the reported cases of Measles in Federal Medical Centre for the year 1996-2005. The data collected are even number of year's data and the approach describing below is used. The two middle years i.e. 2000 and 2001 are coded-1 and 1. The x-value, which is range of odd numbers, are decreasing above and increasing below accordingly. The remaining $\mathrm{x}$-values both proceeding and succeeding the origin years are shown in the table below;

Table 1: Computed Trend of Values

\begin{tabular}{|l|l|l|l|l|l|l|}
\hline YEARS & $\begin{array}{l}\text { YEARLY } \\
\text { TOTAL }\end{array}$ & $\begin{array}{l}\text { CODED } \\
(\mathrm{X})\end{array}$ & $\begin{array}{l}\text { YEARLY } \\
\text { AVG(Y) }\end{array}$ & XY & $\mathrm{X}^{2}$ & $\begin{array}{l}\text { TREND } \\
\text { VALUES }\end{array}$ \\
\hline 1996 & 154 & -9 & 38.00 & -342 & 81 & 43.9 \\
\hline 1997 & 219 & -7 & 54.25 & -379.75 & 49 & 44.9 \\
\hline 1998 & 197 & -5 & 50.25 & -251.25 & 25 & 46.0 \\
\hline 1999 & 197 & -3 & 49.25 & -147.75 & 9 & 27.0 \\
\hline 2000 & 140 & -1 & 35.00 & -35.00 & 1 & 48.2 \\
\hline 2001 & 211 & 1 & 52.75 & 52.75 & 9 & 49.2 \\
\hline 2002 & 208 & 3 & 52.00 & 156.00 & 9 & 50.3 \\
\hline 2003 & 155 & 5 & 38.75 & 193.75 & 25 & 51.4 \\
\hline 2004 & 198 & 7 & 49.50 & 346.5 & 49 & 52.5 \\
\hline 2005 & 260 & 9 & 65.00 & 585.0 & 81 & 53.6 \\
\hline
\end{tabular}

Source: (Computed Trend of Values, 2006)

$\mathrm{Y}_{\mathrm{t}}=\mathrm{a}+\mathrm{bx}$

$\mathrm{Y}_{\mathrm{t}}=48.7+0.5(\mathrm{x})$ ...4

The value calculated in equation 4 is 48.7 (i.e. dividing the sum of column 3 of table 3 by the number of years, which is 10). While the value of $\mathrm{b}$ is obtained by dividing the sum of column 5 ( $\sum x y$ ) by the sum of column 6 $\left(\sum x^{2}\right)$ of same table, Column 7 of the table indicates the Trend Values for each of the 10 years.

\section{Extraction of Trend Values using the Method of Moving Average}

Table 2 shows the computational layout of the trend components for the reported cases of measles in Federal Medical Centre, Makurdi for the year 1996-2005 using a 4 year moving average. The method used is known as centering method. This means that the result of the 4 moving average computed is placed in the centre of every 4 values.

The 2 starting and ending time periods do not have a trend, this omission usually occur when a moving average method is used. Below is a brief summary on how the trend is calculated.

The first total of 154 in column 4 is obtained by summing all the quarterly values on the row of year 1996. i.e. $98+24+8+24=154$ 
The remaining totals in that column for the proceeding years are computed using same format discussed above. The moving average in columns 5 is obtained by dividing each total in column 4 - by 4 i.e.

$\frac{155}{4}=38.5$

$\frac{214}{4}=53.25$

The required trend whose column is titled centered moving average is obtained by taking the average of the first two values in column 5 for the first trend, the third 2 values for the third trend and so on.

Mathematically,

$\underline{38.5+53.25}=45.8$ for the first trend

$\frac{53.25+50.00}{2}=51.6$ for the second trend etc.

The computations are arranged in table 4 below;

Table 2: Calculated Moving-Average

\begin{tabular}{|c|c|c|c|c|c|}
\hline YEARS & QUARTERLY & ORIGINAL DATA & $\begin{array}{l}\text { MOVING TOTALS } \\
\text { OF } 4\end{array}$ & $\begin{array}{l}\text { MOVING AVG OF } \\
4\end{array}$ & $\begin{array}{l}\text { CENTERED } \\
\text { MOVING AVG (t) }\end{array}$ \\
\hline \multirow[t]{7}{*}{1996} & 1 & 98 & & & \\
\hline & 2 & 24 & & & \\
\hline & & & 154 & 38.50 & 45.8 \\
\hline & 3 & 8 & & & \\
\hline & & & 213 & 53.25 & 51.6 \\
\hline & 4 & 24 & & & \\
\hline & & & 200 & 50.00 & 49.5 \\
\hline \multirow[t]{8}{*}{1997} & 1 & 157 & & & \\
\hline & & & 196 & 49.00 & 51.9 \\
\hline & 2 & 11 & & & \\
\hline & & & 219 & 54.75 & 51.4 \\
\hline & 3 & 4 & & & \\
\hline & & & 192 & 48.00 & 48.4 \\
\hline & 4 & 47 & & & \\
\hline & & & 195 & 48.75 & 50.4 \\
\hline \multirow[t]{8}{*}{1998} & 1 & 130 & & & \\
\hline & & & 208 & 50.00 & 51.1 \\
\hline & 2 & 14 & & & \\
\hline & & & 201 & 50.25 & 50.2 \\
\hline & 3 & 17 & & & \\
\hline & & & 203 & 50.75 & 51.1 \\
\hline & 4 & 40 & & & \\
\hline & & & 206 & 51.50 & 50.6 \\
\hline \multirow[t]{8}{*}{1999} & 1 & 132 & & & \\
\hline & & & 203 & 50.75 & 50.00 \\
\hline & 2 & 17 & & & \\
\hline & & & 197 & 49.25 & 45.2 \\
\hline & 3 & 14 & & & \\
\hline & & & 165 & 41.25 & 41.00 \\
\hline & 4 & 34 & & & \\
\hline & & & 163 & 40.75 & 40.00 \\
\hline \multirow[t]{8}{*}{2000} & 1 & 100 & & & \\
\hline & & & 157 & 39.25 & 37.1 \\
\hline & 2 & 15 & & & \\
\hline & & & 140 & 35.00 & 41.0 \\
\hline & 3 & 8 & & & \\
\hline & & & 188 & 47.00 & 47.50 \\
\hline & 4 & 17 & & & \\
\hline & & & 192 & 48.00 & 49.0 \\
\hline \multirow[t]{8}{*}{2001} & 1 & 148 & & & \\
\hline & & & 200 & 50.00 & 51.4 \\
\hline & 2 & 19 & & & \\
\hline & & & 211 & 52.75 & 52.2 \\
\hline & 3 & 16 & & & \\
\hline & & & 207 & 51.75 & 51.75 \\
\hline & 4 & 24 & & & \\
\hline & & & 207 & 51.75 & 51.9 \\
\hline \multirow[t]{5}{*}{2002} & 1 & 144 & & & \\
\hline & & & 208 & 52.00 & 52.0 \\
\hline & 2 & 19 & & & \\
\hline & & & 208 & 52.00 & 55.4 \\
\hline & 3 & 17 & & & \\
\hline
\end{tabular}


Time Series Analysis On Reported Cases Of Measles In Makurdi, Nigeria (1996 - 2005)

\begin{tabular}{|c|c|c|c|c|c|}
\hline & & & 155 & 38.75 & 40.1 \\
\hline & 4 & 28 & & & \\
\hline & & & 166 & 41.50 & 40.62 \\
\hline \multirow[t]{8}{*}{2003} & 1 & 91 & & & \\
\hline & & & 159 & 39.75 & 39.25 \\
\hline & 2 & 30 & & & \\
\hline & & & 155 & 38.75 & 45.6 \\
\hline & 3 & 10 & & & \\
\hline & & & 210 & 52.50 & 51.2 \\
\hline & 4 & 24 & & & \\
\hline & & & 200 & 50.00 & 50.00 \\
\hline \multirow[t]{8}{*}{2004} & 1 & 146 & & & \\
\hline & & & 200 & 50.00 & 49.7 \\
\hline & 2 & 20 & & & \\
\hline & & & 198 & 49.50 & 53.5 \\
\hline & 3 & 10 & & & \\
\hline & & & 230 & 57.50 & 60.4 \\
\hline & 4 & 22 & & & \\
\hline & & & 253 & 63.25 & 63.1 \\
\hline \multirow[t]{6}{*}{2005} & 1 & 178 & & & \\
\hline & & & 252 & 63.00 & 64.00 \\
\hline & 2 & 43 & & & \\
\hline & & & 262 & 65.00 & \\
\hline & 3 & 6 & & & \\
\hline & 4 & 30 & & & \\
\hline
\end{tabular}

Source: (Calculated Moving-Average, 2006)

\section{Extraction of Quarterly Trend Values Using the Least Square Method}

Table 3 shows the calculated trend values of the reported cases of measles in Federal Medical Center from 1996 - 2005 using the Least Square method. Quarterly increment is computed by dividing the value of $b$ by 4 i.e.

$$
\frac{0.54}{4}=0.135
$$

Consider 1996; trend values for the middle year i.e. half of second and half of third is 43.8. Quarterly increment is 0.135 , So the trend value of second quarter and trend values for the preceding years are calculated and arrange in Table 3 thus;

Table 3: Calculated Quarterly Trend Values

\begin{tabular}{|l|l|l|l|l|}
\hline YEAR & Q1 & Q2 & Q3 & Q4 \\
\hline 1996 & 43.6 & 43.7 & 43.9 & 44.0 \\
\hline 1997 & 44.7 & 44.8 & 44.9 & 45.1 \\
\hline 1998 & 45.8 & 45.9 & 46.0 & 46.2 \\
\hline 1999 & 46.8 & 46.9 & 47.0 & 47.2 \\
\hline 2000 & 48.0 & 48.1 & 48.3 & 48.4 \\
\hline 2001 & 49.0 & 49.1 & 49.3 & 49.4 \\
\hline 2002 & 50.1 & 50.2 & 50.4 & 50.5 \\
\hline 2003 & 51.2 & 51.3 & 51.5 & 51.6 \\
\hline 2004 & 52.3 & 52.4 & 52.6 & 53.7 \\
\hline 2005 & 53.4 & 53.5 & & 52.7 \\
\hline
\end{tabular}

Source: (Calculated Quarterly Trend Values, 2006)

\section{Estimation of Seasonal Variation}

Seasonal variation are more or less regular intra-year (within the year) movement recurring year after year. Though seasonal variation generally deals with intra- year movement, yet periodic movement may be characterized as intra- months, intra -weeks, intra-days etc.

Estimation of seasonal variation involves isolating seasonal variation by removing the trend from the original series in order to make the series trend free. The systematic procedures for estimating seasonal variations are shown below;

\section{STEP I}

Find the quarterly total as shown in table 2 for Q1, Q2, Q3, Q4 for each year.

\section{STEP II}

Compute trend for yearly data using least square method. This is shown in table 1 and the explanation is given in equation 14

\section{STEP III}

We find the quarterly trend. This computation is shown in table 2 and explanation in equation 14

\section{STEP IV}

Express each quarterly value as a percentage of the quarterly trend values as shown in table 4 . 
Following the above steps, the results for seasonal variations are arranged in table thus;

Table 4: Estimated Seasonal Variations

\begin{tabular}{|l|l|l|l|l|}
\hline YEARS & Q1 & Q2 & Q3 & Q4 \\
\hline 1996 & 224.7 & 55.0 & 18.2 & 54.5 \\
\hline 1997 & 351.2 & 24.5 & 8.9 & 104.2 \\
\hline 1998 & 283.8 & 30.5 & 36.9 & 86.6 \\
\hline 1999 & 282.0 & 36.2 & 39.8 & 75.6 \\
\hline 2000 & 208.3 & 31.2 & 16.6 & 35.1 \\
\hline 2001 & 302.0 & 38.7 & 32.5 & 56.7 \\
\hline 2002 & 287.4 & 37.8 & 33.7 & 55.4 \\
\hline 2003 & 177.7 & 58.5 & 19.4 & 46.5 \\
\hline 2004 & 279.2 & 38.2 & 19.2 & 41.7 \\
\hline 2005 & 333.3 & 80.4 & 60.7 & 55.8 \\
\hline
\end{tabular}

Source: (Estimated Seasonal Variations, 2006)

To calculate Seasonal Index;

Step 1

Find the total percentage trend values for Q1, Q2, Q3, Q4

This gives us the value shown in the table below:

\begin{tabular}{|l|l|l|l|}
\hline Q1 & Q2 & Q3 & Q4 \\
\hline 2729.8 & 431 & 231 & 612.1 \\
\hline
\end{tabular}

Source: (calculate Seasonal Index, 2006)

Table 5

Step ii

Calculated the mean of percentage values by dividing the values of Qs in the above by $n=10$ (i.e. $400 \cdot 4 / 4=$ 100.12)

Step iii

Compute the average of average i.e. sum percentage totals and divide by 4

Step IV

Divide each total of the percentage trend values by average obtained. This gives seasonal index. The results are in table as shown below:

\begin{tabular}{|l|l|l|l|}
\hline Q1 & Q2 & Q3 & Q4 \\
\hline 272.6 & 43.0 & 23.2 & 61.1 \\
\hline
\end{tabular}

Source: (calculate Seasonal Index, 2006)

Table 6

\section{SEASONALLY ADJUSTED OR DESEASONALIZED DATA}

Table 5 below shows the deseasonalized data for reported cases of Measles in Federal Medical Centre from 1996-2006.

To find the deseasonalized data, 1 followed the followed steps.

1 divide each compute in table 2 by the corresponding Seasonal index of the data computed in table 4 and then convert it to percentage.

The steps describe above gives us the result shown in the table below:

Table 7: Deseasonalized Data

\begin{tabular}{|l|l|l|l|l|}
\hline YEARS & Q1 & Q2 & Q3 & Q4 \\
\hline 1996 & 36.0 & 55.8 & 34.5 & 39.3 \\
\hline 1997 & 57.5 & 25.6 & 17.2 & 80.0 \\
\hline 1998 & 47.6 & 32.5 & 73.3 & 65.5 \\
\hline 1999 & 48.3 & 39.5 & 60.3 & 55.6 \\
\hline 2000 & 36.6 & 35.0 & 34.5 & 27.8 \\
\hline 2001 & 54.2 & 44.2 & 68.9 & 45.8 \\
\hline 2002 & 52.7 & 44.1 & 73.2 & 45.8 \\
\hline 2003 & 33.3 & 69.7 & 43.1 & 39.3 \\
\hline 2004 & 53.5 & 46.5 & 63.1 & 38.8 \\
\hline 2005 & 65.2 & 100.0 & & 36.0 \\
\hline
\end{tabular}

Source: (Deseasonalized Data, 2006)

Estimation of Cyclical and Irregular Variation

Table 8 shows the computed values or estimated values of cyclical and irregular variations. 
The following steps were followed.

\section{Step 1}

Compute percentage trend values; this is already in Table 4 and procedures of getting it is clearly stated in step IV

\section{Step II}

Subtract 100 from each percentage value; this is called Deviation from $100 \%$. The figures obtained gives cyclical and irregular variations.

Table 10: Estimated Values of Cyclical and Irregular Variation

\begin{tabular}{|l|l|l|l|l|}
\hline YEARS & Q1 & Q2 & Q3 & Q4 \\
\hline 1996 & 124.7 & -55.0 & -81.8 & -45.5 \\
\hline 1997 & 251.2 & -75.5 & -91.5 & 4.2 \\
\hline 1998 & 183.8 & -69.5 & -63.1 & -13.4 \\
\hline 1999 & 182 & -63.8 & -70.2 & -24.4 \\
\hline 2000 & 108.3 & -68.8 & -83.4 & -64.9 \\
\hline 2001 & 202 & -61.3 & -67.5 & -66.3 \\
\hline 2002 & 187.4 & -62.2 & -80.6 & -43.3 \\
\hline 2003 & 77.7 & -41.5 & -81.0 & -53.5 \\
\hline 2004 & 179.2 & -61.8 & -83.3 & -58.3 \\
\hline 2005 & 233.3 & -19.6 & -44.2 \\
\hline
\end{tabular}

Source: (: Estimated Values of Cyclical and Irregular Variation, 2006)

\section{FORECASTING}

Method of Least Squares for forecasting:

Assuming $\mathrm{x}$ represent the number of years and given the trend line equation. $\mathrm{Y}_{\mathrm{t}}=48.7+0.54 \mathrm{x}$

We can predict for the year 2006 - 2010 for the given values of $X=11,13,15,17$ respectively.

This gives us the result thus:

\begin{tabular}{|l|l|l|l|l|}
\hline 2006 & 2007 & 2008 & 2009 & 2010 \\
\hline 54.6 & 55.7 & 56.8 & 57.9 & 58.9 \\
\hline
\end{tabular}

Table 11

Quarterly method of Least Squares for forecasting

Having done our forecast for the year 2006-2010 it is obvious to know the increment per each quarter for number of years represented. Following the same procedure described in 4.2.0 we the result thus:

\begin{tabular}{|l|l|l|l|l|}
\hline Years & Q1 & Q2 & Q3 & Q4 \\
\hline 2006 & 54.4 & 54.5 & 54.6 & 54.8 \\
\hline 2007 & 55.5 & 55.6 & 55.8 & 56.0 \\
\hline 2008 & 56.6 & 56.7 & 56.8 & 57.0 \\
\hline 2009 & 58.0 & 57.8 & 57.9 & 58.1 \\
\hline 2010 & 58.7 & 58.8 & 58.9 & 59.1 \\
\hline
\end{tabular}

Source: (Quarterly method of Least Squares for forecasting, 2006)

\section{Results and Interpretation}

The data collected for this study were based on quarterly report cases of measles in Federal Medical Centre, Makurdi Benue State from 1996 - 2005 a period of ten (10) years.

A critical observation of the graph shows that in the trend obtained

$\mathrm{Y}_{\mathrm{t}}=48.7+0.54(\mathrm{x})$

The coefficient $\mathrm{X}=0.54$ is the gradient of the slope of the line. 48.7 is the intercept on the $\mathrm{Y}$ axis that is the beginning of each quarter of the year, the number of reported cases of measles is 0.54 .

Again, observation of the data depicts the existence of long term trend movement from upward to downward of the time series data. The fluctuation of the time series can be attributed to whether changes within the year e.g. hot season, cold season etc.

However, at the first quarter of each successive year shows that the total reported cases of measles are very high. Also, from the graph the average number of reported cases of measles for second and third quarter for each successive year is relatively small. Unlike the second and third quarter, the graph shows that the fourth quarter is relatively high. 


\section{Conclusion}

In the undergone chapters, we introduced the bases of time series analysis. We defined the four (4) components of time series like long term trend, seasonal components, cyclical components and irregular components. The various methods of estimating the trend have been applied as discussed in the foregone chapters. The methods are least square method and moving average method.

The Least square method was the best for accuracy, reliability and prediction purposes. On the other hand the moving average clearly determines the nature of the trend whether linear or non-linear if the period of the average is chosen appropriately.

Generally, from the graph, the period of ten years of study from 1996 - 2005 will did experienced that the cases of measles in Federal Medical Center is higher from the last to the first quarter in each successive year. This shows that there are serious cases of measles recorded at the end and the beginning of each year (November, December, January, February and March) in Federal Medical Center, Makurdi.

November to March is known to be hot season in Makurdi metropolis. This clearly shows that measles occurs most during hot seasons.

\section{Recommendations}

Decision makers need to examine variables measured over time in an effort to learn about the past. We study the past to make better decision about the future.

Therefore, from the analysis above, Benue State Ministry of Health should know which time of the year is moat suitable to carry out immunization against measles - that is, during the seasons that the cases of measles are very low (April, May, June, July, August and September).

Finally, according to the forecast made by the researcher, the cases of measles will be on increase every year in Federal Medical Centre, Makurdi. Though the increment would not be much, but if it is not properly handled, as time goes on the increment will result to a very high one.

\section{References}

[1]. Adamu, S.O and Tinuku I. Johnson (1975). Statistics for Beginners, Onibonoje Pree and Book Industries (Nig.) Ltd. Pp 188-201

[2]. Donald, H. Sanders (1990). Statistic; A fresh Approach ( $4^{\text {th }}$ Edition $)$ ELBS publishing company, London. Pp. $298-372$

[3]. Eguda, S.O (2006), Time Series Analysis, Unpublished Lecture note,Department.

[4]. Gupta, C. B and Vijay Gupta (1989). An Introduction to Statistical Methods, Vinkas Puublishing House PVT Ltd, India. Pp. 295-366

[5]. Harper, W.M (1971). Statistics, Mc Donald and Evans Limited Britain. Pp. 572-690

[6]. Moses, Yode Omotosho (2003). College and University Statistics, Yosode Book Publishers, Moniya Ibadan. Pp. 134-201

[7]. Murrey. R. Spiegel (1972). Schaum's Outline Series (First Edition) Mc-Graw-Hill Book Co. New-york.Pp. 422-563

[8]. Onomo, Okechukwu Chinedu (1997). Time Series Analysis on Rainfall Pattern in Makurdi from 1968-1982, Unpublished Project, Department.

[9]. Richmond and Samuel (1957). Principle of Statistical Analysis, the Ronald Press Company. Pp.271-346

[10]. Thomas, R. Dyckman and L. Joseph Thomas (1977). Fundamental Statistics for Business and Economics, Prentice- Hall, Inc. Englewood Cliffs, New Jersey, USA. Pp. 588-625 